\title{
AS PROPOSIÇÕES DO ENFOQUE CTS NOS LIVROS DIDÁTICOS DE CIÊNCIAS DO 9 ANO
}

\author{
Jucelino Cortez ${ }^{1}$ \\ Armando Foscarin Neto ${ }^{2}$
}

\begin{abstract}
RESUMO
Este artigo apresenta o resultado de uma pesquisa qualitativa nos livros didáticos contemplados no Plano Nacional do Livro Didático, da disciplina de Física do 9o ano do Ensino Fundamental, utilizados na cidade de Passo Fundo, região norte do Rio Grande do Sul. O objetivo principal deste trabalho está voltado para a análise das formas e das disposições com que os conteúdos são apresentados e trabalhados nestes livros, buscando identificar em quais oportunidades propostas pelas obras pode-se identificar a presença das proposições da abordagem Ciência - Tecnologia - Sociedade (CTS). Dessa forma, pretende-se também oferecer, aos gestores e professores da Educação Básica, subsídios no momento da escolha desta ferramenta. Com a pesquisa identificou-se, por meio do desvelamento de categorias, como e quando tais proposições são identificadas, conforme o referencial teórico que é utilizado neste estudo.
\end{abstract}

Palavras-chave: Ensino de Física. Enfoque CTS. Livro didático.

\section{THE PROPOSITIONS OF THE STS APPROACH IN THE TEACHING BOOKS OF THE 9TH YEAR SCIENCES}

\section{ABSTRACT}

This article presents the results of a qualitative research with the didactic books included in the National Plan of the Didactic Book of the discipline of Physics of the 9th year of elementary education, used in the city of Passo Fundo, northern region of Rio Grande do Sul. Of this work is focused on the analysis of the forms and dispositions with which the contents are presented and worked on in these books, trying to identify in which opportunities proposed by the works can identify the presence of the propositions of the Science - Technology - Society (STS) approach. In this way, it is also intended to offer, to managers and teachers of basic education, subsidies when choosing this tool. With the research, we identified, through the unveiling of categories, how and when such propositions are identified, according to the theoretical framework used in this study.

Keywords: Physics Teaching. STS Approach. Textbook.

Recebido em: 22/2/2019

Aceito em: $2 / 9 / 2019$

\footnotetext{
${ }^{1}$ Graduação em Matemática com habilitação em Física (1996) e Especialização em Metodologia do Ensino da Matemática (1998) pela Universidade de Passo Fundo. Mestrado em Ensino de Física (2014) e Doutorado em Educação em Ciências (2018) pela Universidade Federal do Rio Grande do Sul. Professor na área de Física da Universidade de Passo Fundo, nos cursos de Engenharia, Química e Física, e professor de Física do Doctor Pré-vestibular. Participa de projetos de extensão voltados para o ensino de Física e formação continuada de professores da Educação Básica, desenvolvendo também pesquisas sobre o enfoque Ciência-Tecnologia-Sociedade no ensino das Ciências. http://lattes.cnpq. br/6812333905063139. https://orcid.org/0000-0001-8642-5605. jucelinocortez@gmail.com

${ }^{2}$ Mestrando do Programa de Pós-Graduação em Ensino de Ciências e Matemática da Universidade de Passo Fundo. Graduado em Física - Licenciatura - pela Universidade de Passo Fundo. Membro do grupo de pesquisa em Cultura Digital da Universidade de Passo Fundo e colaborador do programa Escola de Hackers da prefeitura de Passo Fundo. Professor de Física, Ciências e Astronomia no Ensino Fundamental, Escola St. Patrick. Mentor de aprendizagem criativa no B-LAB Learning Space. Áreas de interesse: Robótica Educacional e Astronomia. http://lattes.cnpq.br/5680814445858929. https://orcd.org/0000-0001-6195-560X. armando.foscarin@gmail.com
} 
A educação formal, na atualidade, constitui um dos temas mais problemáticos, complexos e dinâmicos, principalmente nos países que apresentam baixos índices de aproveitamento escolar, como o Brasil. Para Rosa e Rosa (2005), parte desta realidade deve-se à forma de construção dos processos educacionais.

O processo de educação escolarizado no Brasil vem sendo construído ao longo dos anos fortemente apoiado em questões de ordem política, o que de certo modo tem proporcionado um descaso e uma falta de compromisso com a formação cultural, moral, intelectual e científica do nosso povo. O ensino das Ciências é um reflexo desta situação educacional, já que não existe uma política nacional para o desenvolvimento da Ciência (ROSA; ROSA, 2005, p. 3).

O Ministério da Educação, como órgão responsável pelas políticas públicas junto as orientações relacionadas à educação, tem publicado, nas últimas décadas, uma série de documentos visando a balizar os rumos a serem seguidos. Servem de exemplos, desde a Lei de Diretrizes e Bases da Educação Nacional (LDB) de 1996, as publicações dos Parâmetros Curriculares Nacionais (PCNs), as Orientações Curriculares Nacionais (OCNs), as Diretrizes Curriculares Nacionais (DCNs) e, mais recentemente, a Base Nacional Curricular Comum (BNCC).

Paralelamente a estas orientações oficiais, o governo federal também instituiu o Programa Nacional do Livro Didático (PNLD). Este Programa é destinado a avaliar e a disponibilizar obras didáticas, pedagógicas e literárias, entre outros materiais, com o intuito de dar apoio à prática educativa. Assim o livro didático, seguindo parâmetros específicos e critérios de distribuição, acaba por ser a maior fonte de informação e de suporte para os professores. Conforme análise de Garcia,

[...] é razoável se pensar que a distribuição universalizada de livros didáticos para os alunos do Ensino Médio, ocorrida na última década, deve ter trazido para o interior das salas de aula uma série de situações que, por serem recentes, ainda necessitam ser estudadas, tendo em vista que na maior parte das escolas públicas, anteriormente, eram raras as situações em que os alunos possuíam livros didáticos (2012, p. 1).

Neste contexto, Lajolo (1996) aborda em seu trabalho a importância que o livro didático assume em sala de aula, visto que ele acaba sendo largamente utilizado e referenciado nas aulas. Para esta autora, o livro didático "[...] acaba determinando conteúdos e condicionando estratégias de ensino, marcando, pois, de forma decisiva, o que se ensina e como se ensina o que se ensina" (p. 4).

Mesmo assim, referindo-se ao Programa Internacional de Avaliação de Alunos (Pisa), Zompero, Figueiredo e Vieira (2016) afirmam que "[...] a colocação geral do estudante brasileiro em 2015 entre 76 países participantes se atesta na 60a colocação" (p. 88). Tais índices, segundo estes autores, refletem a qualidade da educação nacional, desvelando um quadro preocupante e digno de profundas reflexões na busca por meIhorias. No ensino das Ciências Naturais e, em especial da Física, tem-se o mesmo quadro. Segundo Moreira: 
Além da falta e/ou despreparo dos professores, de suas más condições de trabaIho, do reduzido número de aulas no Ensino Médio e da progressiva perda de identidade da Física no currículo nesse nível, o ensino da Física estimula a aprendizagem mecânica de conteúdos desatualizados. Estamos no século XXI, mas a Física ensinada não passa do século XIX (2011, p. 6).

$\mathrm{Na}$ tentativa de tornar a educação formal mais relacionada com as necessidades que emergem na sociedade atual, tornando o processo mais interessante e útil aos professores e, principalmente, aos educandos, surgiu a abordagem Ciência-Tecnologia-Sociedade (CTS) no ensino das Ciências. Nas palavras de Santos e Mortimer:

O objetivo central da educação de CTS no Ensino Médio é desenvolver a alfabetização científica e tecnológica dos cidadãos, auxiliando o aluno a construir conhecimentos, habilidades e valores necessários para tomar decisões responsáveis sobre questões de Ciência e tecnologia na sociedade e atuar na solução de tais questões (2002, p. 5).

Assim, conforme os referenciais teóricos abordados, que consideram que a abordagem CTS pode ser um caminho para melhorar a qualificação do ensino oferecido nas escolas de Educação Básica e, ciente de que o livro didático constitui, atualmente, a principal fonte de suporte aos professores, surge a dúvida que motiva esta pesquisa: Como os livros didáticos de Ciências no 9o ano do Ensino Fundamental abordam os conteúdos de Física e como tal abordagem pode ser relacionada com o enfoque CTS?

O objetivo principal deste trabalho consiste, portanto, em identificar nos livros didáticos de Ciências do 9o ano do Ensino Fundamental, na parte referente aos conteúdos de Física, a forma com que estes valorizam os pressupostos do enfoque CTS, possibilitando assim, como objetivo secundário, oferecer subsídios, aos gestores e professores da Educação Básica, para discussões e análise no momento de escolha do livro didático.

Para atingir tal intento optou-se pela pesquisa de abordagem qualitativa, valorizando e identificando as diferentes situações e ideias que nem sempre podem ser representadas por valores numéricos, natureza aplicada, objetivos exploratórios e procedimentos bibliográficos de um estudo de caso (GERHARDT; SILVEIRA, 2009).

Este estudo de caso terá como corpo de pesquisa os livros didáticos de Ciências do 9 o ano do Ensino Fundamental adotados por algumas escolas públicas na cidade de Passo Fundo, região norte do Rio Grande do Sul. Nesses livros faz-se a busca e a análise dos principais pontos que caracterizam a abordagem CTS, elencando assim, categorias escolhidas a priori, conforme as prerrogativas destacadas no referencial teórico.

Este artigo, após esta introdução, está organizado para abordar o referencial teórico, a metodologia utilizada na pesquisa, seguindo com a análise dos livros e finalizando com nossas considerações e conclusões.

\section{REFERENCIAL TEÓRICO}

O enfoque CTS no ensino das Ciências tem suas origens no movimento CTS, ocorrido em um período histórico que sucede a Segunda Guerra Mundial (RIBEIRO, 2015). Este movimento teve duas origens distintas: a norte-americana e a europeia. Estas influenciaram ainda, uma terceira origem, conhecida como latino-americana. Ainda quanto às origens, segundo Ribeiro: 
Sua emergência está relacionada a uma reavaliação crítica dos papéis desempenhados pela Ciência e Tecnologia nas sociedades contemporâneas, num período marcado por tratados de limitações de testes nucleares, a eclosão de movimentos ambientalistas e a crítica acadêmica à tradição filosófica positivista de caracterização da Ciência (BAZZO; VON-LINSINGEN; PEREIRA, 2003 apud RIBEIRO, 2015, p. 16).

Estas mudanças de concepção sobre a utilidade da Ciência e da Tecnologia levam então, a academia europeia, no início da década de 70, a iniciar estudos sobre a relação entre o caminhar da Ciência e da Tecnologia e a influência deste processo sobre a sociedade. No mesmo período inicia-se também na América do Norte, com uma disposição mais popular e ativista, um movimento semelhante questionando e criticando os impactos da evolução científica e tecnológica (MIRANDA, 2013). De forma concomitante, a vertente sul-americana, conhecida também por Pensamento Latino-Americano em CTS (Placts), surge na década de 60, com suas primeiras indagações acerca da influência das políticas públicas no trato com a relação entre os avanços científicos e a qualidade de vida das sociedades (CORTEZ; DEL PINO, 2017).

Com estas motivações, o movimento CTS passa a ter influência em três frentes distintas: nas políticas públicas, nas pesquisas acadêmicas e na educação (CEREZO, 1998). Segundo Santos (2007), no campo da educação o movimento origina uma forma diferenciada de abordagem de ensino, valorizando, nas palavras deste pesquisador,

[...] uma proposta curricular de CTS pode ser vista como uma integração entre educação científica, tecnológica e social, em que conteúdos científicos e tecnológicos são estudados juntamente com a discussão de seus aspectos históricos, éticos, políticos e socioeconômicos (p. 2).

Neste cenário, de várias origens e campos de ação, o movimento CTS pode ser resumido como uma confluência de diversas intenções e características que, no campo da educação, recebem diversas categorizações. Optamos nesta pesquisa, considerando a relevância dos estudos, pelas classificações propostas pelos pesquisadores J. Ziman (1994) e Glein Aikenhead (1994), que apontam as proposições do enfoque CTS, conforme a Tabela 1 a seguir:

Tabela 1 - Proposições do enfoque CTS

\begin{tabular}{|l|l|}
\hline \multicolumn{2}{|c|}{ Categorias de Ziman } \\
\hline $\begin{array}{l}\text { Enfoque na aplicação } \\
\text { da Ciência }\end{array}$ & $\begin{array}{l}\text { A Ciência deve ser encarada como uma construção de conhecimentos } \\
\text { diferenciados, onde se encontram aplicações e efeitos colaterais, } \\
\text { implicando assim, perigos e benefícios ao utilizá-la. O enfoque CTS } \\
\text { valoriza currículos que têm esta visão de Ciência em detrimento dos } \\
\text { currículos tradicionais. }\end{array}$ \\
\hline Enfoque vocacional & $\begin{array}{l}\text { Este enfoque valoriza uma formação que utilize conhecimentos } \\
\text { científicos tecnológicos para que sejam úteis em uma possível carreira } \\
\text { profissional. }\end{array}$ \\
\hline Interdisciplinaridade & $\begin{array}{l}\text { As relações entre a Ciência, a Tecnologia e a Sociedade agregam } \\
\text { diferentes áreas do saber, assim, a abordagem CTS tem como uma } \\
\text { das suas principais características, o enfoque interdisciplinar para o } \\
\text { ensino das Ciências, transpondo, com esta atitude, a fragmentação } \\
\text { de conteúdos por meio do diálogo entre as disciplinas. }\end{array}$ \\
\hline
\end{tabular}




\begin{tabular}{|c|c|}
\hline Enfoque histórico & $\begin{array}{l}\text { Este enfoque refere-se ao conceito de construção do conhecimento } \\
\text { científico em determinada situação histórica e social, desmistificando } \\
\text { o conceito do conhecimento pronto, revelando uma série de fatores } \\
\text { que permeiam o desenvolvimento das Ciências. }\end{array}$ \\
\hline Enfoque filosófico & $\begin{array}{l}\text { Este enfoque está interligado diretamente ao enfoque histórico, visto } \\
\text { que, se considerarmos que a Ciência é algo em contínua evolução } \\
\text { em determinada realidade histórica, podemos sugerir ao estudante a } \\
\text { ideia que a Ciência pode não ser uma verdade dogmática, absoluta e, } \\
\text { portanto, mesmo o método científico pode ser questionado. }\end{array}$ \\
\hline Enfoque sociológico & $\begin{array}{l}\text { Este enfoque é também um dos mais importantes da abordagem CTS, } \\
\text { propondo que o estudante deve ter condições de entender a Ciência } \\
\text { e a tecnologia como instituições sociais e, sendo assim, geram novos } \\
\text { saberes em um determinado contexto social e histórico. }\end{array}$ \\
\hline Problematização & $\begin{array}{l}\text { A problematização ajuda na transposição dos conhecimentos, } \\
\text { diminuindo a distância entre os conceitos e a realidade cotidiana } \\
\text { dos alunos, por meio do uso de temas, muitas vezes de cunho social, } \\
\text { como impactos ambientais e econômicos, que sejam de interesse de } \\
\text { todos os atores do processo. }\end{array}$ \\
\hline \multicolumn{2}{|r|}{ Categorias de Aikenhead } \\
\hline Contextualização & $\begin{array}{l}\text { Segundo Aikenhead, devem-se abordar conteúdos de forma integrada } \\
\text { e conectada a situações do cotidiano do estudante, seguindo uma } \\
\text { tendência integrativa entre conteúdos abordados em sala de aula } \\
\text { com situações nas quais os fenômenos podem ser analisados. }\end{array}$ \\
\hline Tomadas de decisão & $\begin{array}{l}\text { O ensino com o enfoque CTS potencializa o desenvolvimento da } \\
\text { conscientização por parte do educando, de utilizar aspectos históricos, } \\
\text { filosóficos e epistemológicos envolvidos nas Ciências, capacitando-o } \\
\text { assim, para a possibilidade de tomadas de decisão no âmbito de uma } \\
\text { responsabilidade social na qual ele está inserido. }\end{array}$ \\
\hline $\begin{array}{l}\text { Currículo orientado no } \\
\text { aluno }\end{array}$ & $\begin{array}{l}\text { Segundo o enfoque CTS, os procedimentos de ensino e aprendizagem } \\
\text { devem ser orientados no aluno, levando em consideração que este } \\
\text { precisa desenvolver o conhecimento científico de forma útil, que } \\
\text { valorize a formação de um sujeito capaz de intervir no meio em que } \\
\text { vive. }\end{array}$ \\
\hline $\begin{array}{l}\text { Formação crítica para o } \\
\text { exercício da cidadania }\end{array}$ & $\begin{array}{l}\text { Esta leva em consideração que o ensino das Ciências não pode ser } \\
\text { baseado em repasse de conteúdos, da forma tradicional e bancária. } \\
\text { Esta dimensão prevê que questões científico-tecnológicas passam, } \\
\text { inevitavelmente, por processos sociais, históricos, filosóficos e } \\
\text { culturais. Para a abordagem CTS é de suma importância a construção } \\
\text { do conhecimento para formação de atitudes e valores éticos e morais } \\
\text { nos estudantes. }\end{array}$ \\
\hline
\end{tabular}

Fonte: Dados dos autores (2018).

Tais categorias, como veremos no próximo item, serão importantes para a compreensão e para a definição das categorias utilizadas neste trabalho.

É importante salientar que estas proposições não são enfoques exclusivos da abordagem CTS, destacando-se que, por exemplo, inserções no ensino que valorizam a interdisciplinaridade, a contextualização e a problematização são defendidas por diversos autores, como Fazenda (1979) e Japiassu (1976), sem necessariamente estarmos nos referindo à utilização da abordagem CTS. 


\section{REFERENCIAL METODOLÓGICO}

Com a intenção de analisarmos a presença das proposições que caracterizam o enfoque CTS nos livros didáticos do 9o ano do Ensino Fundamental, nos capítulos que abordam conteúdos de Física, optamos por realizar esta pesquisa utilizando uma abordagem qualitativa de caráter exploratório. Para tal intento recorremos ao procedimento de estudo de caso, fazendo nesta etapa uma análise bibliográfica dos livros que compõem o corpo de pesquisa.

A principal característica da pesquisa qualitativa, segundo Goldenberg (2011), está na intenção do aprofundamento da compreensão de um grupo social, de uma organização, não se preocupando com representatividade numérica. Os pesquisadores que adotam a abordagem qualitativa opõem-se ao pressuposto que defende um modelo único de pesquisa para todas as Ciências, uma vez que as Ciências Sociais têm sua especificidade, o que pressupõe uma metodologia própria.

Quanto ao procedimento, optou-se pelo estudo de caso, considerando que este método oferece a possibilidade de aquisição de conhecimento do fenômeno estudado a partir da exploração intensa de um único caso. Para Goldenberg (2011), o estudo de caso não é uma técnica específica, mas uma análise holística, que considera a unidade social estudada como um todo, tanto para um indivíduo, uma família, uma instituição, quanto para uma comunidade, com o objetivo de compreendê-los em seus próprios termos.

O estudo em questão foi focado somente nos livros didáticos de Ciências do 9o ano, adotados nas escolas públicas de Passo Fundo, totalizando cinco obras, conforme a Tabela 2. São elas :

Tabela 2 - Livros didáticos de Ciências do 9o ano adotados nas escolas públicas de Passo Fundo

\begin{tabular}{|l|l|l|}
\hline Livro 1 & L1 & $\begin{array}{l}\text { CANTO, Eduardo Leite do; CANTO, Laura Celloto. Ciências naturais: aprendendo } \\
\text { com o cotidiano 2. 6. ed. São Paulo: Moderna, 2017. }\end{array}$ \\
\hline Livro 2 & L2 & CARNEVALE, Maria Rosa et al. Ciências: 9. 4. ed. São Paulo: Moderna, 2016. \\
\hline Livro 3 & L3 & $\begin{array}{l}\text { GOWDAK, Demétrio; MARTINS, Eduardo. Ciências novo pensar: Química-Física 9. } \\
\text { São Paulo: FTD, 2017. }\end{array}$ \\
\hline Livro 4 & L4 & $\begin{array}{l}\text { GEWANDSZNAJDER, Fernando. Ciências: matéria e energia. 2. ed. São Paulo: } \\
\text { Ática, 2016. }\end{array}$ \\
\hline Livro 5 & L5 & BARROS, Carlos; PAULINO, Wilson. Ciências: 9. 6. ed. São Paulo: Ática, 2016. \\
\hline
\end{tabular}

Fonte: Acervo dos autores, 2018.

Nestes livros, o procedimento de pesquisa empregado foi de análise bibliográfica que, segundo Gil (2008, p. 50), "é desenvolvida a partir de material já elaborado constituído principalmente de livros e artigos científicos".

Assim, com o corpo de pesquisa e os procedimentos bem definidos, realizamos uma análise minuciosa procurando identificar situações expostas nas obras que pudessem ser relacionadas com as características da abordagem CTS. Com o intuito de direcionar melhor as relações, optamos por adotar categorias que foram escolhidas a priori, conforme os estudos de Cortez e Del Pino (2017). São elas: (a) a problematização e a contextualização; (b) a interdisciplinaridade e os enfoques histórico, filosófico e sociológico; (c) a inclusão de temas sociais e questões socio-científicas e (d) a formação cidadã 
do educando e a valorização da discussão acerca do papel da Ciência e da Tecnologia. Estas categorias, conforme os autores, fazem uma síntese das proposições elencadas por Aikenhead (1994) e Ziman (1994) que caracterizam a abordagem CTS.

Em cada categoria procura-se, por meio de textos, apêndices ou imagens, desvelar situações presentes nos livros, que estejam relacionadas com as respectivas características do enfoque CTS que estão contempladas na categoria.

Sabemos que o uso da abordagem CTS vai muito além dos recursos apresentados nos livros didáticos, mas também somos cientes da importância que os mesmos têm no cotidiano de sala de aula, como uma ferramenta norteadora nas sequências dos conteúdos e nas formas de abordá-los. Nesta linha de pensamento, Schäffer (1988) afirma que

[...] o livro didático não é, em si, responsável por um bom ou medíocre desempenho. Como instrumento ele serve a um fim, às intenções de um plano de trabalho elaborado. Por esta razão importa, sobretudo, que o professor tenha clareza quanto a seus objetivos (p. 3).

Desta forma, valorizamos nesta pesquisa a busca pelas relações entre as prerrogativas do enfoque CTS e a forma com que os livros abordam os conteúdos, considerando que a qualidade das atividades didáticas deve-se a uma soma de fatores e ao diálogo entre as diferentes estratégias de ensino.

Considerando que o escopo deste trabalho está voltado para a análise dos livros, a fim de oferecer subsídios para que os professores possam discutir junto aos seus pares, visando a elencar as obras que melhor contribuam como suporte em suas aulas, procura-se construir um levantamento que possa ser utilizado de forma generalizada em outras obras, independentemente do ano e do nível de ensino. Ou seja, procura-se apontar situações que os livros destacam ou deveriam destacar na busca de um ensino mais completo e atualizado, diante das novas demandas sociais.

Assim, na intenção de externar uma forma de análise dos livros, que seja útil também para outras obras e em outras versões do PNLD, utilizaremos a denominação de L1, L2, L3, L4 e L5 para cada um dos livros, conforme a Tabela 2, quando for necessário citá-los.

\section{ANÁLISE DOS LIVROS}

\section{Quanto à Problematização e à Contextualização}

A primeira categoria analisada neste trabalho foi a problematização e a contextualização, segundo as concepções de Ziman (1994) e de Aikenhead (1994), respectivamente. Para estes autores a problematização pode ser identificada como a prática de promover um ensino com conteúdos que estejam envolvidos em situações cotidianas ou abordados nos meios de comunicação de massa, como temas envolvendo problemas de trânsito, urbanização, entre outros. Já a contextualização, na visão de Aikenhead (1994), pode ser entendida como uma forma de abordar conteúdos de Ciências de maneira conectada e integrada com o cotidiano dos alunos ou a contextos que eles tenham conhecimento. 
Sendo assim, após a análise dos livros didáticos, podemos relatar diversos casos de contextualização. Em todos os livros, por exemplo, nos capítulos que se referem ao estudo do movimento, podemos encontrar diversas imagens, em vários formatos, visando a trazer o cotidiano do aluno por meio de alusões ao esporte, ao trânsito e a outras situações envolvendo pessoas trabalhando.

Além das imagens esportivas e das situações envolvendo indivíduos trabalhando, nos livros L1, L2 e L4 encontramos uma ótima sequência didática abordando o uso de alavancas, retratando situações muito comuns no cotidiano, como crianças brincando numa praça, pessoas erguendo objetos, relacionando tais situações com os conhecimentos científicos. É muito comum nestas obras a alusão a imagens de ferramentas como quebra-nozes, vassouras, carrinhos de mão e outros equipamentos mecânicos, visando à contextualização das teorias abordadas.

No livro L4 destaca-se o uso de um apêndice extra ao conteúdo, em que também se aborda, de maneira exauriente, argumentos que valorizam as contextualizações elencadas anteriormente, com a ajuda de quadros "especiais", distribuídos ao longo da obra.

Das obras analisadas, nota-se também uma forte vocação à valorização desta categoria, começando pelos títulos dos apêndices oferecidos. Servem de exemplos os itens "Ciência no Dia a Dia" e "Ciência e Ambiente", com quadros que se encarregam de relacionar os conhecimentos científicos com o cotidiano por meio de problematizações e contextualizações.

Nas cinco obras ainda é possível identificar alusões às questões envolvendo clima, uso de roupas e aquecedores, transformações e geração de energia, buscando sempre exemplos em textos e imagens envolvendo paisagens de inverno, usinas hidrelétricas e equipamentos tecnológicos.

O uso de temas polêmicos, como impactos ambientais, pode ser citado em algumas obras, como um aporte à problematização. No apêndice "Ciência e ambiente", por exemplo, o autor resgata questões sobre gelo e vida nas regiões geladas, trazendo o exemplo das condições em que a temperatura leva a água a congelar, suas peculiaridades com relação à densidade e, portanto, à possibilidade de vida mesmo com a superfície de rios e lagos congelados, tecendo comentários como aquecimento global e consumo de energia elétrica para aquecimento das casas.

Em suma, podemos claramente perceber que os conteúdos abordados nos livros didáticos recorrem constantemente ao uso da contextualização e, em muitos casos, ao uso da problematização, relacionando assim a forma de expor os conteúdos e as proposições da abordagem CTS elencadas nesta categoria. Nesse aspecto, corroborando este viés, Santos (2007) defende que, nos currículos CTS, os conteúdos são usados como agentes de transformação social, criando debates sobre questões pertinentes à realidade social dos educandos. Para este autor isso não significa o ato de simplificar os conteúdos e sim ressignificá-los socialmente.

É importante salientar que ao fazer este aporte os livros didáticos estão atendendo às orientações governamentais como PCNs e DCNs, concordando ainda com as teorias de John Ziman (1994), sobre o uso da problematização. 


\section{Quanto à Interdisciplinaridade e aos Enfoques Histórico, Filosófico e Sociológico}

Para Ziman (1994), as relações entre a Ciência, a Tecnologia e a Sociedade agregam diferentes áreas do saber. Assim, a abordagem CTS tem como uma das suas principais dimensões o enfoque interdisciplinar para o ensino das Ciências, transpondo com esta atitude a fragmentação de conteúdos por meio do diálogo entre as disciplinas.

Corroborando esta visão, a autora Ivani Fazenda afirma que a interdisciplinaridade é uma tarefa difícil a ser desenvolvida devido à estruturação curricular nas escolas brasileiras, inferindo assim que a compartimentalização passa a ser "o principal empecilho à construção de um trabalho interdisciplinar" (FAZENDA, 1979, p. 139).

Neste aspecto, procurando superar as dificuldades destacadas, as obras analisadas trazem conceitos e exemplos que podem ser tratados de maneira interdisciplinar. Por exemplo, no livro L1, o autor resgata situações envolvendo a Biologia e a Educação Física, em estudos sobre atrito e movimento das articulações do corpo humano. Na mesma obra, tratando da acústica, o autor recorre novamente a exemplos interdisciplinares relacionados com teoria musical, com a Biologia e com a Matemática, abordando conceitos relacionados ao estudo do som e do ultrassom com o comportamento de diferentes animais encontrados na natureza.

No L2 e no L4 é possível evidenciar o uso da interdisciplinaridade em abordagens envolvendo conceitos de pressão, temperatura e a Biologia dos seres vivos, questões relacionando eletricidade e magnetismo com as características de elementos químicos e ainda, no $L 3$ e no $L 5$, aparecem textos e imagens relacionando conceitos de consumo de energia elétrica com questões relacionadas à Geografia das regiões de maior ou menor consumo. Neste contexto, segundo Bovo (2005), ao propormos a interdisciplinaridade, saímos da concepção fragmentada que as disciplinas podem deixar, possibilitando uma visão unitária do conhecimento, graças ao diálogo entre as diferentes áreas do conhecimento.

Ainda buscando pela recorrência desta categoria, é possível destacar, em todas as obras, mesmo variando a intensidade com que isto acontece, a relação com o contexto histórico em que as descobertas científicas acontecem. Em todos os livros analisados os autores resgatam partes dos períodos históricos e, em alguns casos (L2, L4, L5), valoriza-se até um pouco das concepções filosóficas que influenciaram as Ciências.

É comum nos livros alusões às descobertas de Arquimedes (L5), referindo-se principalmente aos casos das roldanas, dos espelhos esféricos e da coroa, aos experimentos de Galileu Galilei e Newton (L1, L2, L3, L4 e L5), resgatando fatos que, muitas vezes, estão mais relacionados às estórias do que à História, como o caso da pena e da bigorna de Galileu e o episódio da queda da maçã na cabeça de Newton. Ainda nestas obras é possível destacar alguns contextos abordando os primeiros inventos relacionados à eletricidade, como as descobertas de Tales de Mileto e a Grécia antiga. No L1, por exemplo, o autor ainda resgata os trabalhos de Christiaan Hugens, citando que este utilizou os descobrimentos científicos de Galileu para construir o relógio de pêndulo. Nesta mesma obra, assim como no L3, os autores abordam a gravitação universal, recorrendo aos embates das concepções filosóficas em torno do geocentrismo e do heliocentrismo, relacionando assim questões políticas, sociais e até religiosas. 
Outra importante relação tecida entre as diferentes áreas do conhecimento e os contextos envolvidos pode ser identificada no L3, quando o autor aborda durante o estudo da termologia a Revolução Industrial e seus contextos sociais e econômicos, destacando os trabalhos de Watt, James P. Joule, Carnot e William Thompson.

No livro L5, por exemplo, é possível destacar ainda outras histórias, como os trabalhos de Santos Dumont, em seu 14-Bis, o Concorde francês e sua velocidade supersônica, bem como as condições gerais que envolveram a criação das Leis de Newton, abordando a vida deste cientista inglês e as condições de sua época. Em um contexto mais recente, merece destaque no livro $L 2$, o recorte sobre a vida e as teorias de Stephen Hawking, bem como das novas concepções do cosmos e de energia.

Assim, percebe-se que nos mais diferentes momentos, os usos da interdisciplinaridade e do contexto histórico estão presentes em todos os livros analisados. Quanto ao uso do contexto filosófico e sociológico, percebe-se que são poucas as ocasiões em que o autor propõe reflexões acerca destes aportes, podendo citar, como exemplo, referências às concepções astronômicas em diferentes épocas, formas de relações de trabalho antes e depois da Revolução Industrial e impactos tecnológicos com o uso da eletricidade.

Mesmo estas obras contextualizando historicamente e filosoficamente a evolução de conhecimentos como a Astronomia, faz-se importante mencionar que predomina nestes livros, quando fazem o uso do contexto histórico, a concepção de que as leis da Física são descobertas oriundas de um desconhecimento quase que total da teoria desvelada, criando assim no educando uma visão distorcida da evolução das Ciências. Pode-se citar, como exemplos desta constatação, o fato de estas obras relacionarem as Leis de Newton com a queda da maçã, ou ainda a invenção da máquina térmica de James Watt, sem mencionar as máquinas de Denis Papin, Thomas Savery e Thomas Newcomen.

Neste aspecto, segundo Gurgel e Mariano (2008), é preciso que se observe a necessidade de permitirmos uma formação junto ao educando, que the possibilite uma visão de que a Ciência e a Tecnologia não estão desconectadas da sociedade e dos interesses atrelados à relação. Para estas pesquisadoras, o homem e as descobertas científicas constituem-se como entidades interdependentes da realidade social, providas assim de erros e acertos e tais desdobramentos devem estar sempre presentes no ensino das Ciências.

\section{Quanto à Inclusão de Temas Sociais e Questões Sociocientíficas}

Esta categoria reúne duas fortes dimensões do enfoque CTS que, segundo Aikenhead (1994), são de fundamental importância para a formação plena do educando. Estas proposições levam em consideração que o ensino das Ciências não pode ser baseado em repasse de conteúdos, da forma tradicional e bancária (FREIRE, 1983). Esta visão prevê ainda que questões científico-tecnológicas, inevitavelmente, passam por processos sociais, históricos, filosóficos e culturais. Para a abordagem CTS é de suma importância a construção do conhecimento para formação de atitudes e valores éticos e morais nos estudantes (PRAIA; CACHAPUZ, 2005), justificando-se, assim, esta categorização. 
Buscando por estas características na forma de abordar os conteúdos dos livros, é possível identificar algumas situações nas quais os autores utilizam, como forma de relacionar os conteúdos com situações práticas, eventos envolvendo questões sociais e sociocientíficas. Serve de exemplo a referência aos problemas enfrentados pelos cadeirantes nas calçadas e nos acessos aos estabelecimentos (L1) quando se discute máquinas simples; a análise das questões envolvendo velocidade e aceleração nas leis de trânsito, bem como os riscos e as consequências dos acidentes (L4); a abordagem do consumo e da transformação de energia, relacionando tudo isso com a construção de usinas hidrelétricas, os impactos ambientais e as fontes renováveis de energia (L1, L4 e L5).

Ainda nesta categoria destaca-se a referência aos problemas ambientais causados pelo crescimento tecnológico que acabam abalando o frágil equilíbrio do ecossistema e, por consequência, afetam as comunidades mais marginalizadas da sociedade (L4). Já no livro L5 o autor resgata uma comparação entre países e suas formas de produção de energia, propondo aos educadores discussões quanto ao uso consciente da energia. Esta obra cita ainda um texto que traz informações sobre a produção de energia elétrica a partir de fontes renováveis. Relata a condição do Brasil com relação à produção de energia eólica e ainda traça uma breve relação com o mesmo tipo de produção em outros países, como Holanda, Dinamarca e Alemanha. Neste quadro o livro também cita a necessidade da interação entre produção de energia e a produção de máquinas e materiais que contribuam para a conscientização da reciclagem e da economia de energia elétrica.

É possível destacar também a preocupação com a inclusão de temas ambientais, por parte do autor no livro L5, quando este aborda discussões sobre as atividades tecnológicas desenvolvidas pelo ser humano e suas consequências relativas ao aquecimento global. Na mesma obra, em outro capítulo, o autor destaca que muito do que evoluímos em tecnologia deve-se ao grande investimento em pesquisas bélicas, durante os períodos armamentistas ou pós-guerra, deixando possibilidades ao professor de disponibilizar aos seus educandos momentos para a análise sobre como se deve usar a Ciência que criamos, ponderando se esta é realmente neutra e inquestionável, como nos moldes positivistas, ou se todo o avanço científico está entrelaçado às questões de interesse capital e cultural.

Faz-se necessário, porém, mencionar que tais aportes às questões socio-científicas e aos temas sociais aparecem com uma frequência muito pequena, valorizando o uso e os impactos causados pela tecnologia, sem abordar um histórico mais detalhado de erros e acertos nas pesquisas científicas, deixando, assim, claro predomínio da concepção linear de benefício infinito causado pela Ciência. Para Cerezo (1998), esta concepção é oriunda do período pós-Segunda Guerra Mundial, quando muitos cientistas acreditavam e influenciaram a sociedade em torno da concepção positivista de que, quanto mais Ciência produzirmos, mais tecnologia teremos e assim, mais conforto e bem-estar social seriam fornecidos para todos.

Fica evidenciada esta visão, por exemplo, quando os autores destas obras abordam o uso das usinas hidrelétricas para a geração de energia e não mencionam os impactos ambientais ( $L 3$ e L4), quando resgatam o salto tecnológico causado pela revolu- 
ção industrial, sem destacar a grande poluição do ar causada por tais avanços e quando abordam a necessidade de reciclar, mas não consideram os custos e os impactos causados pelos processos de reciclagem.

\section{Quanto à Formação Cidadã do Educando e à Valorização da Discussão Acerca do Papel da Ciência e da Tecnologia}

Esta quarta categoria agrega, segundo os autores que referenciam esta pesquisa, os principais fins da abordagem CTS. Segundo Santos e Mortimer (2002), o maior objetivo desta abordagem está voltado para a formação crítica e ética do educando e, para estes pesquisadores, a capacidade de compreensão do papel que a Ciência e a Tecnologia deveriam ocupar na sociedade constitui uma das maiores competências que devem estar agregadas na formação plena dos estudantes.

Das obras analisadas, pode-se perceber, na maioria das abordagens dos conteúdos, certa concepção positivista da produção científica, valorizando a evolução tecnológica, sem considerar os custos sociais e ambientais para tal crescimento. Mesmo assim, no L5 é possível detectar a valorização com que o autor aborda o uso da eletricidade, incentivando para a conscientização em relação ao consumo excessivo de energia elétrica, sugerindo reflexões sobre a escolha e a real necessidade de aquisição de equipamentos como celulares, aquecedores e outros eletro-portáteis.

O livro L5, nesta categoria, merece um destaque especial, pois aborda em diversos conteúdos a dificuldade em transformar energia, incentivando discussões sobre o uso consciente da eletricidade, propondo análises sobre outros tipos de energia e, no caso das chamadas "renováveis", o autor valoriza a consideração dos baixos impactos ambientais que tais fontes acarretam à sociedade.

Predomina nos mais variados momentos, porém, a exposição de conteúdos de uma forma geral, em que o autor parte de uma situação-problema ou da "descoberta de um cientista" de forma isolada e exitosa, deixando assim a clara concepção de uma Ciência que nasce e evolui de forma neutra e inquestionável na sua beneficência. Para citar alguns exemplos, no L1 quando o texto aborda a aceleração gravitacional está escrito "O valor de g se altera de modo significativo ao nos movimentarmos dos polos em direção à linha (imaginária) do Equador terrestre. O valor médio da aceleração da gravidade é: $g=9,8 \mathrm{~m} / \mathrm{s}$ ". Na mesma linha, o L4 ao abordar o conceito de potência, por exemplo, "A potência é o trabalho realizado por unidade de tempo ou, em outras palavras, a razão entre o trabalho realizado $(\tau)$ e o intervalo de tempo gasto para realizá-lo $(\Delta t)$, veja a equação que indica isso: $P=\tau / \Delta t$ ". Estes exemplos que podem ser encontrados nas obras analisadas e que reforçam o que foi relatado anteriormente, ou seja, passa-se a ideia da Ciência como "algo pronto", uma descoberta feita por um cientista brilhante no interior de seu laboratório de pesquisa.

$\mathrm{Na}$ tentativa de superar estas concepções, Conrado e El-Hani (2010) discorrem sobre a falta de abordagens, ainda no Ensino Fundamental, tratando discussões sobre como a ciência se desenvolve na sociedade, as relações mútuas de influência entre sociedade e tecnologia e a importância do papel do cidadão, como sujeito crítico e ético, diante das questões tecnocientíficas. 


\section{CONSIDERAÇÕES FINAIS}

O objetivo deste trabalho não estava voltado para a construção de uma crítica às editoras e aos autores de livros, mas como citado anteriormente nos objetivos, pretendia-se verificar a presença das proposições da abordagem CTS nos livros didáticos e, consequentemente, oferecer subsídio para a comunidade escolar na análise e seleção de livros para o ano letivo. Assim, podemos concluir que em todos os livros analisados encontram-se exemplos das proposições CTS utilizadas para a análise deste trabalho, logicamente de maneira diferente e singular para cada um dos livros didáticos.

Notamos que os argumentos que mais se adaptam à visão CTS estão relacionados com conteúdos envolvendo Movimento, Ondulatória, Calorimetria e Óptica. Nestes tópicos, o viés interdisciplinar é o mais explorado. Nota-se também, talvez pela complexidade do assunto e haja vista a faixa etária dos educandos, que este viés ainda é pouco utilizado em estudos envolvendo Eletricidade e Eletromagnetismo, não considerando assim que educandos de todas as faixas etárias, hoje em dia, estão em contato, de uma maneira ou outra, com diversos tipos de tecnologia, desde fontes de produção de energia ao sinal de Internet, consoles de game, televisão, etc.

A faixa etária dos alunos em questão, portanto, poderia ser um imediato incentivo à produção de material com um forte enfoque CTS, pois facilitaria a visão de uma educação e de um mundo interligado, especialmente no mundo científico, quando se percebe que, na maioria dos casos, preconceitos e estereótipos com a figura do cientista estão presentes.

Segundo a análise feita, desvelamos que todos os livros citados, de uma forma ou de outra, trazem ao educador alguns exemplos ou situações que estão consoantes ao enfoque CTS. Constatamos que a contextualização e a interdisciplinaridade são as proposições mais comuns presentes nestas obras, favorecendo um processo de ensino não fragmentado e relacionado ao cotidiano dos educandos.

Os contextos históricos e sociais, por sua vez, estão presentes nas obras em uma demanda inferior, valorizando eventos clássicos como as histórias de Aristóteles, Galileu e Newton. Mesmo com algumas referências à Revolução Científica e à Revolução Industrial, abordando um pouco as questões sociais e filosóficas, é possível evidenciar que, na maioria das obras, a ciência é apresentada como algo que evolui de forma independente e desconectada dos contextos políticos e sociais, reverberando ao educando uma visão distorcida e simplista da evolução da ciência.

Ainda é necessário destacar, como fruto da análise realizada nos livros, a pouca incidência de abordagens envolvendo a formação ética e cidadã dos educandos. Nota-se que predomina nas obras a concepção linearista de ciência, incentivando assim uma visão voltada para o benefício inquestionável dos avanços científicos. Este processo, promovido em crianças e adolescentes, não contribui para o desenvolvimento de uma formação crítica e questionadora diante das inúmeras tecnologias que o mercado oferece.

Por fim, consideramos que cabe aos professores e gestores das escolas tirar o máximo proveito das formas com que os livros didáticos apresentam os conteúdos que devem ser desenvolvidos. Faz-se necessário, porém, que estes mesmos atores busquem uma formação contínua e atualizada aos contextos, visando a apresentar os temas cien- 
tíficos por meio das diversas áreas do conhecimento, de forma integrada, valorizando o desenvolvimento da ciência e as questões sociais envolvidas nas diferentes épocas de nossa História.

Destacamos que a utilização do livro é somente um dos aspectos da complexa tarefa de ensinar Ciências e, mais especificadamente, neste caso, Física a alunos do 9 o ano do Ensino Fundamental. Acreditamos que as considerações e exemplos citados neste trabalho podem ajudar os professores na tarefa de analisar os livros didáticos, possibilitando com isso ações que complementem o seu uso, promovendo uma formação plena, ética e cidadã aos educandos.

\section{REFERÊNCIAS}

AIKENHEAD, Glein. STS education: international perspectives on reform. New York: Teachers College Press, 1994.

BARROS, Carlos; PAULINO, Wilson. Ciências: 9. 6. ed. São Paulo: Ática, 2016.

BOVO, Marcos Clair. Interdisciplinaridade e transversalidade como dimensões da ação pedagógica. Revista Urutágua, Maringá, n. 7, ago./nov. 2005.

BRASIL. Guia PNLD 2017 Anos finais Ciências. Brasília, DF: Ministério da Educação, 2016.

BRASIL. Ministério da Educação. Base Nacional Curricular Comum - BNCC. Disponível em: https://bit. Iy/2IbTdNM. Acesso em: 15 set. 2018.

BRASIL. Ministério da Educação. Secretaria de Educação Básica. Diretrizes Curriculares Nacionais Gerais da Educação Básica. Brasília: MEC; SEB; Dicei, 2013.

BRASIL. Parâmetros Curriculares Nacionais: terceiro e quarto ciclos do ensino fundamental: ciências naturais. Brasília, DF: SEF; MEC, 1998.

CANTO, Eduardo Leite do; CANTO, Laura Celloto. Ciências naturais: aprendendo com o cotidiano 2. 6. ed. São Paulo: Moderna, 2017.

CARNEVALE, Maria Rosa et al. Ciências: 9. 4. ed. São Paulo: Moderna, 2016.

CEREZO, José Antonio López. Ciencia, tecnología y sociedad: el estado de la cuestión en Europa y Estados Unidos. Revista Iberoamericana de Educación, n. 18, 1998.

CONRADO, Dália M.; EL-HANI, Charbel N. Formação de cidadãos na perspectiva CTS: reflexões para o ensino de ciências. In: SIMPÓSIO NACIONAL DE ENSINO DE CIÊNCIA E TECNOLOGIA, 2., 2010. Ponta Grossa. Anais [...]. Ponta Grossa: UTFPR, 2010. p. 1-16.

CORTEZ, Jucelino; DEL PINO, José Claudio. A abordagem CTS e as Diretrizes Curriculares Nacionais para o Ensino Médio - implicações para uma Nova Educação Básica. Revista Brasileira de Ensino de Ciência e Tecnologia, v. 10, n. 3, 2017. Disponível em: https://bit.ly/2TLWlqu. Acesso em: set. 2017.

FAZENDA, Ivani Catarina (org.). Integração e interdisciplinaridade no ensino brasileiro: efetividade ou ideologia? São Paulo: Loyola, 1979.

FREIRE, Paulo. Pedagogia do oprimido. 12. ed. Rio de Janeiro: Paz e Terra, 1983.

GARCIA, Nilson Marcos Dias. Livro didático de física e de ciências: contribuições das pesquisas para a transformação do ensino. Educar em Revista, Curitiba, n. 44, p. 145-163, abr./jun. 2012.

GERHARDT, Tatiana Engel; SILVEIRA Denise Tolfo. Métodos de pesquisa. Universidade Aberta do Brasil UAB/UFRGS e pelo Curso de Graduação Tecnológica - Planejamento e Gestão para o Desenvolvimento Rural da SEAD/UFRGS. Porto Alegre: Editora da UFRGS, 2009.

GEWANDSZNAJDER, Fernando. Ciências: matéria e energia. 2. ed. São Paulo: Ática, 2016.

GIL, Antonio Carlos. Como elaborar projetos de pesquisa. 4. ed. São Paulo: Atlas, 2008.

GOLDENBERG, Mirian. A arte de pesquisar: como fazer pesquisa qualitativa em Ciências Sociais. 12. ed. Rio de Janeiro: Record, 2011.

GOWDAK, Demétrio; MARTINS, Eduardo. Ciências novo pensar: Química-Física 9. São Paulo: FTD, 2017.

GURGEL, Célia M. do A.; MARIANO, Gláucia E. Concepções de neutralidade e objetividade da ciência e tecnologia na formação de professores de ciências: argumentos para a inserção da história e sociologia da ciência na construção do conhecimento científico. Revista Brasileira de Ensino de Ciência e Tecnologia, v. 1, n. 1, jan./abr. 2008.

JAPIASSU, Hilton. Interdisciplinaridade e patologia do saber. Rio de Janeiro: Imago, 1976. 
LAJOLO, Marisa. Livro didático: um (quase) manual de usuário. Em Aberto, Brasília, n. 69, v. 16, jan./mar. 1996.

MIRANDA, Elisangela. Matias. Tendências das perspectivas Ciência, Tecnologia e Sociedade (CTS) nas Áreas de Educação e Ensino de Ciências: uma análise a partir de teses e dissertações brasileiras e portuguesas. 2013. Tese (Doutorado em Educação) - Universidade Federal de São Carlos, São Carlos, 2013.

MOREIRA, Marco Antonio. Teorias de Aprendizagem. 2. ed. São Paulo: EPU, 2011.

PRAIA, Jorge; CACHAPUZ, Antonio. Ciência-tecnologia-sociedade: um compromisso ético. Revista lberoamericana de Ciencia Tecnología y Sociedad, Buenos Aires, v. 2, n. 6, p. 173-194, 2005.

RIBEIRO, Thiago. Vasconcelos. O subcampo brasileiro de pesquisa em ensino de Ciências CTS (Ciência-Tecnologia-Sociedade): um espaço em construção. 2015. Dissertação (Mestrado em Educação em Ciências e Matemática) - Universidade Federal de Goiás, Goiânia, 2015.

RICARDO, Elio Carlos. A problematização e a contextualização no ensino das ciências: acerca das idéias de Paulo Freire e Gérard Fourez. ENCONTRO NACIONAL DE PESQUISA EM EDUCAÇÃO EM CIÊNCIAS, 4., Bauru, 2003.

ROSA, Cleci Werner da; ROSA, Álvaro Becker da. Ensino de Física: objetivos e imposições no ensino médio. Revista Electrónica de Enseñanza de las Ciencias, v. 4, n. 1, 2005.

SANTOS, Wildson Luiz Pereira dos. Contextualização no ensino de ciências por meio de temas CTS em uma perspectiva crítica. Ciência e Ensino, v. 1, n. especial, nov. 2007.

SANTOS, Wildson Luiz Pereira dos; MORTIMER, Eduardo Fleury. Uma análise de pressupostos teóricos da abordagem C-T-S (Ciência-Tecnologia-Sociedade) no Contexto da Educação Brasileira. Ensaio - Pesquisa em Educação em Ciências, Belo Horizonte, v. 2, n. 2, p. 133-162, 2002.

SCHÄFFER, Neiva Otero. O livro didático e o desempenho pedagógico: anotações de apoio à escolha do livro Texto. Boletim Gaúcho de Geografia, Porto Alegre, v. 16, n. 1, p. 3-16, out. 1988. Disponível em: https://bit.ly/2AmUOJR. Acesso em: 10 set. 2018.

ZIMAN, John. The rationale of STS education is in the approach. In: SOLOMON, J.; AI-KENHEAD, G. STS education: international perspectives on reform. New York: Teachers College Press, 1994.

ZOMPERO, Andreia Freitas; FIGUEIREDO, Helenara Regina Sampaio; VIEIRA, Karen Mayara. O desempenho de alunos brasileiros e a avaliação pisa: alguns aspectos para discussão. Revista Góndola, Enseñanza y Aprendizaje de Las Ciencias, Bogotá, v. 11, n. 1, p. 86-99, 24 jun. 2016. 